ways of being that make dissent, not escape, a necessity" (p. 188).

It is García Canclini's contention that sociology enables us to read new global relations of interdependence, while anthropology enables us to grasp the density of these "intercultural" interactions. Together with the above modeling of the world and its generalities (including "collapse," "dissent," "hegemonies," "periods," "art worlds," "cultures," and "classes"), such sociology-anthropology enables us to make these assertions: "Art attempts to narrate, to trans- late indecisions and enigmas, to make visible the tension between rootedness and traveling" (p. 82); "we live in the age of unframed art," art practice having moved from objectbased practices to context-based ones (p. 101); "art exists because we live in tension between what we desire and what we lack, between what we would like to name and what is contradicted or disagreed upon by society" (p. 127); and "[works of art] situate themselves in a prior moment, when the real is possible, when it has not yet broken down" (p. xiv).

\title{
Applied Evolutionary Anthropology: Darwinian Approaches to Contemporary World Issues by Mhairi A.Gibson and David W. Lawson, eds.
}

\author{
Advances in the Evolutionary Analysis of Human Behaviour series. New York: Springer Science Business Media, 2014. \\ 299 pp.
}

DOI: 10.1111/aman.12262

\section{Michael Price}

Brunel University London

I appreciate the value of both evolutionary behavioral science and applied social research, and I see no better foundation for the latter than the former. I admit to being a bit wary, however, that some current enthusiasm for applied research stems from cynicism about the value of basic research. The editors of Applied Evolutionary Anthropology note that funding agencies demand increasingly that anthropologists "prove their worth" by demonstrating applied value (p. 4). I hope this doesn't imply that these agencies define "worth" as "immediate short-term value." The uses of basic research are often unanticipated and may take decades to emerge. Just as Isaac Newton didn't foresee taking us to the moon, evolutionary behavioral scientists couldn't have predicted how their basic research would be used in works such as Applied Evolutionary Anthropology.

Having said all that, it certainly is important to demonstrate the applied value of evolutionary behavioral science, and Applied Evolutionary Anthropology succeeds impressively in this regard. Chapters focus on social issues as diverse as population sex ratios, warfare, collective agriculture, microfinance, altruistic punishment, and public health (including maternal and infant health, nutrition, behavior change, and the effects of socioeconomic status on health). Below I'll discuss a few chapters that left a particularly big impression and that are suggestive of the book's overall tenor.

An evolutionary perspective can generate novel solutions to problems of public health, and this is exemplified most starkly in Gillian Pepper and Daniel Nettle's chapter. They present a simple and powerful behavioral-ecological model to account for why people with lower socioeconomic statuses tend to engage in unhealthy behavior. Because these people's lives tend to involve high "extrinsic mortality" risks (i.e., uncontrollable risks like violent crime), they have reduced incentives to avoid even those risks over which they have some control (e.g., quitting smoking). This model is used to radically consolidate existing explanations for these health effects (from nine to two competing explanation classes), deepen these explanations, and generate novel interventions (e.g., a good way to encourage healthier lifestyle choices in these environments would be to reduce extrinsic mortality risks).

I particularly enjoyed Bram Tucker's chapter on collective agriculture, as I've conducted research in this area myself. Collective agriculture is regarded here in terms of "group-level cultural adaptation" (p. 17), and many useful applications of evolutionary theory are made. I wondered, however, whether too much group-level focus would distract from the problem of individualistic free riding, which has been identified as a key barrier to successful collective action cross-culturally (Ostrom 2000; Price 2006).

Mhairi Gibson's chapter demonstrates not just the benefits of taking an evolutionary approach but also the unanticipated dangers of not taking one. She reports on a development scheme that introduced water taps to Arsi Oromo agropastoralists in Ethiopia. This scheme succeeded in reducing women's effort expended on water collection but had the unintended consequence of dramatically increasing their fertility, leading to an unsustainable strain on resources. Had life history theory been used to predict that these women would divert their conserved work effort energy toward reproductive effort (Gibson argues convincingly on pp. 69-71 that reduced workload was the key mediating variable here), the need for interventions 
(e.g., contraceptive provisioning) would have been easier to foresee.

Robert Layton's chapter is one of the most ambitious in that he tackles the particularly big problem of war. He reaches the reasonable conclusion that human nature is neither peaceful nor warlike, and he seems to suggest that it is flexibly adapted for both, with behavioral output depending on environmental input (p. 196). I was confused, however, about why he portrays this view as being radically opposed to that of Steven Pinker, who he describes as holding a "genetic[ally] determinis[tic]" view of humans as inflexibly violent creatures (p. 195). On the contrary, Pinker's (2011) main message is not that violence is inevitable but that cultures have become vastly less violent over time, as the peaceful aspects of human nature have prevailed increasingly over the violent ones (hence his title, The Better Angels of Our Nature). As the views of Layton and Pinker seem compatible, it's not clear why a conflict is perceived here.

Academic debates shouldn't distract from the book's main function as a demonstration of evolutionary anthropol- ogy's added social value or from the fact that it represents a landmark achievement in this regard. It is a difficult challenge to bridge the gap between basic and applied research in evolutionary behavioral science. This book meets that challenge by demonstrating convincingly, in chapter after chapter, how these applications are assisting anthropologists in their everyday efforts to improve people's lives.

\section{REFERENCES CITED}

Ostrom, Elinor

2000 Collective Action and the Evolution of Social Norms. Journal of Economic Perspectives 14(3):137-158.

Pinker, Steven

2011 The Better Angels of Our Nature: The Decline of Violence in History and Its Causes. London: Penguin.

Price, Michael E.

2006 Judgments about Cooperators and Freeriders on a Shuar Work Team: An Evolutionary Psychological Perspective. Organizational Behavior and Human Decision Processes 101(1):20-35.

\section{Leviathans at the Gold Mine: Creating Indigenous and Corporate Actors in Papua New Guinea by Alex Golub.}

Durham: Duke University Press, 2014. 264 pp.

DOI: 10.1111/aman.12263

\section{Pierre-Yves Le Meur}

Institut de Recherche pour le Développement

"It is not easy to separate 'Ipili culture' from 'the mine", (p. 9), writes the author of Leviathans at the Gold Mine. This intriguing assertion, at least from a classically culturalist standpoint, is followed by an explanatory outline that lies at the core of Alex Golub's argument: "Decades of mining in Porgera have made kinship and landownership contested topics, even in areas not directly affected by mining" (p. 9). The story told in this book can be read on two intertwined levels. First, the book tells the story of the encounter between local people and a foreign corporation in a seemingly remote part of Papua New Guinea, the Porgera Valley. It focuses on the Porgera gold-mining project, which stands at a specific historical juncture marked by the Bougainville crisis, the closure of Panguna copper mine in 1989, and the desperate search for revenues in which the Papua New Guinean government has engaged to compensate for this loss while also having demonstrated its inability to "operate a mine in the face of local opposition. The result was a moment of opportunity that the Ipili seized, becoming one of the most active and successful groups in pressing claims against the state and transnational capitalism" (p. 8). Second, the book pro- poses a Latourian "sociology of associations," which explores the translation processes resulting in the making of powerful macroactors or leviathans - bureaucracy, mine, customary landowners, clans, the Ipili-who come to structure the mining arenas in various human and nonhuman guises.

The book is organized as "a long zoom out" (p. 21) that starts with a Manchesterian extended case study, tracing an eventually unsuccessful 18-month-long negotiation between "the Ipili" and "the mine" in different arenas (ch. 1) and culminating in a reappraisal of the postcolonial discourses and debates on national identity in Papua New Guinea, with a focus on an elusive ethnicity and a constructivist indigenous conception of patrimony (ch. 4). The local taste for innovation and the integration of foreign items goes hand in hand with an allergy to "leviathans" as "cold" and to institutional organizational forms, be they mine or state: "Papua New Guineans may be pre-adapted to entrepreneurship, but not to its institutionalization” (p. 196). Chapters 2 and 3 bridge the gap between case study and generalization through the adoption of historical and ethnographic lenses respectively.

Golub aims to analyze within a common theoretical framework the proliferation and interplay of actors in the arenas, in which resource access and identity distribution are negotiated along with as the efficacy and actual "concreteness" of macroactors able to "sign an agreement given the fact... [they have] no hands" (p. 4). Chapters 1 and 